\title{
ADOLESCENTS WITH PREEXISTING AUTOIMMUNE RHEUMATIC DISEASES DURING COVID-19 QUARANTINE: HIGH RISK OF MENTAL ISSUES AND IMPACT IN PHYSICAL HEALTH
}

Bianca Pires Ihara ${ }^{1, \star}$, Lívia Maria Lindoso Lima ${ }^{1}$, Debora Narumi Demitrol Setoue ${ }^{1}$, Nicolas Yamada Tanigava ${ }^{1}$, Juliana Russo Simon $^{1}$, Claudia Alejandra Ayala Strabelli ${ }^{1}$, Reinan Tavares Campos ${ }^{1}$, Camilla Astley Amaral Pedroso ${ }^{1}$, Sofia Mendes Sieczkowska ${ }^{1}$, Rosa Maria Rodrigues Pereira ${ }^{1}$, Nádia Emi Aikawa ${ }^{1}$, Kátia Tomie Kozu¹, Adriana Maluf Elias ${ }^{1}$, Bruno Gualano ${ }^{1}$, Lígia Bruni Queiroz ${ }^{1}$, Caio Borba Casella ${ }^{1}$, Guilherme Vanoni Polanczyk ${ }^{1}$, Clovis Artur Almeida da Silva ${ }^{1}$, Lúcia Maria Mattei de Arruda Campos ${ }^{1}$

1. Hospital das Clínicas HCFMUSP, Universidade de São Paulo, São Paulo (SP), Brazil.

*Corresponding author: bia.ihara@gmail.com

\section{BACKGROUND}

Social isolation due to the COVID-19 pandemic can impact physical and mental health of adolescents with autoimmune rheumatic diseases (ARD), as a result of interruption in school, cultural and physical activities, and reduction in outpatient visits. The objective of this study is to evaluate physical and mental health issues in this population during quarantine, as well as parameters of disease activity.

\section{METHODS}

A cross-sectional study included 155 adolescents with ARD and 105 healthy controls. They answered an online self-reported survey of demographic data, daily and school routine, physical activities and COVID information during the SARS-CoV-2 pandemic. A validated instrument, named strengths and difficulties questionnaire (SDQ), assessing psychological functioning were also on-line evaluated. Disease activity parameters and treatment were retrospectively evaluated from patients' medical records. Patients were assigned in two groups according to the four-band categorization of self-reported SDQ: abnormal score (corresponding to moderate/ severe scores with cut-off points $\geq 18$ ) and normal/borderline score (cut-off points $<18$ ).

\section{RESULTS}

Among patients, 56\%had JIA, 29\%JSLE and 15\%JDM. No differences were found regarding gender, ethnicity and current age between patients and controls. ARD more often studied at public schools (76\%vs.64\%, $p=0.046$ ), and performed school homework for shorter periods (41\%vs.55\%, $p=0.047$ ) compared to controls. Main source of information about COVID-19 was media (TV, radio, internet) for all participants. Patients and controls had similar abnormal total difficulties scores of SDQ (31\%vs.32\%, p=0.901). Among ARD, those with abnormal SDQ total difficulties scores were directly associated to sleep problems $(\mathrm{OR}=2.658 ; 95 \% \mathrm{Cl}=1.282-5.510$, $\mathrm{p}=0.009)$. Worsening in family financial situation appeared as a risk factor tendency $(\mathrm{OR}=1.454 ; 95 \% \mathrm{Cl}=0.997-2.121, \mathrm{p}=0.052)$. Concerning abnormal emotional score of SDQ female gender and once again sleep problems raised as risk factors (OR=2.490; 95\% $\mathrm{Cl}=1.027-6.040, \mathrm{p}=0.044$ and $\mathrm{OR}=4.647 ; 95 \% \mathrm{Cl}=2.216-9.743, \mathrm{p}<0.001$, respectively). More than 85\% of $\mathrm{ARD}$ attended our outpatient clinics during the study period and up to $20 \%$ of them presented worsening of disease activity scores and/or increased therapy. However, no correlations were found between disease activity scores and mental health instruments.

\section{CONCLUSION}

During COVID-19 quarantine patients and controls had notable SDQ scores. Among patients, sleep disorders raised as the main risk factors associated with worse total difficulties scores and emotional domain of SDQ. This finding must warn assistant physicians to advise their patients about sleeping care. It is possible that the distress observed in patients during the pandemic might contribute to disease flares.

\section{KEYWORDS}

COVID-19 quarantine, mental health, physical health, sleep disturbs 